\title{
EVALUATION OF THE VERTICAL MARGINAL GAP OF CADICAM LITHIUM DISILICATE AND ZIRCONIA REINFORCED LITHIUM SILICATE GLASS CERAMICS BEFORE AND AFTER THERMOMECHANICAL CYCLING
}

\author{
Mohamed R Mahmoud*, Ahmed M Yousri**, Moamen A Abd El-kader***
}

\begin{abstract}
Statement of the problem: The use of machinable monolithic lithium disilicate (LD) ceramics has been frequently used in fixed prosthodontics with well-known marginal adaptation values. However, information about the newly developed zirconia reinforced lithium silicate glass ceramics (ZLS) regarding marginal adaptation is of concern. Aim of the study: The aim of this study was to evaluate the vertical marginal gap of CAD \CAM lithium disilicate and zirconia reinforced lithium silicate glass ceramics before and after thermomechanical cycling. Methodology: Twenty crowns were fabricated using Cerec in-Lab CADICAM system, and divided into two groups (10 IPS. E.max CAD and 10 VITA SUPRINITY). The completed crowns were cemented on epoxy resin die and the vertical marginal gap was evaluated. The cemented crowns were subjected to thermomechanical cycling for 75000 cycles and the vertical marginal gap was evaluated again after cyclic loading. The collected data was statistically analyzed using Student t-test and Paired t-test and the significance level was set at $\mathrm{P} \leq 0.05$.
\end{abstract}

Results: There was no statistical significant difference between the two tested groups or between measurements before and after thermomechanical cycling. Conclusion: Neither the material type nor the thermomechanical cycling has an effect on the vertical marginal gap measurements of the two tested groups.

\section{INTRODUCTION}

All ceramic restorations are a metal-free alternative with excellent aesthetic, mechanical and biocompatibility properties ${ }^{(1)}$.

Nowadays, glass ceramics are mainly lithium disilicate-based pressable ingots or $\mathrm{CAD} / \mathrm{CAM}$ blocks. These restorations have satisfactorily served as monolithic restorations ${ }^{(2)}$.

Zirconia reinforced lithium silicate glass ceramic (ZLS) for dental CAD/CAM restorations has been introduced to the dental market. This glass ceramic is enriched with zirconia ( $\approx 10 \%$ by weight) to combine the positive benefits of translucency of glass ceramics and mechanical properties of zirconia ( $\mathrm{ZrO} 2)$. Incorporation of zirconia particles is claimed to improve mechanical properties by interruption of crack propagation ${ }^{(3,4)}$.

One of the most critical aspects for success of prosthetic restoration is to achieve optimal marginal adaptation. Improper marginal adaptation will lead to the accumulation of bacterial plaque and can cause gingival inflammation, caries, pulp and periodontal lesions, finally resulting in failure of the restoration ${ }^{(5,6)}$. Mechanical failure due to fatigue could occur during mastication as a result of direct contact between maxillary and mandibular teeth and finally limits the survival probability and lifetime of the restorations ${ }^{(7)}$.

\footnotetext{
* Demonstrator, Crown and Bridge Department, Faculty of Dental Medicine (Cairo-Boys), Al-Azhar University. ** Assistant Professor, Crown and Bridge Department, Faculty of Dental Medicine (Cairo-Boys), Al-Azhar University. *** Lecturer, Crown and Bridge Department, Faculty of Dental Medicine (Cairo-Boys), Al-Azhar University.
} 
In vitro testing of dental materials provides part of the view over the prosthetic behavior of restorations with simplicity in performance Mechanical cyclic loading tests are aimed at stimulating the conditions of mastication in the oral cavity by inducing alternate stresses in the samples thus reflects the behavior of restorations under function ${ }^{(8,9)}$.

The null hypothesis is there is no difference in the vertical marginal gap between CADICAM lithium disilicate and zirconia reinforced lithium silicate glass ceramics before and after thermomechanical cycling.

\section{MATERIALS AND METHODS}

An upper premolar acrylic tooth was selected and mounted vertically in special designed mold by aids of parallometer device, then the tooth was prepared for placement of all-ceramic crowns using a milling survivor and diamond stones to ensure accurate preparation parameters. The preparation design included a $1.0-\mathrm{mm}$ chamfer, and a $12^{\circ}$ convergence angle. An occlusal reduction of $2 \mathrm{~mm}$ was prepared and controlled by guidance grooves and rubber index taken before reduction.

Special mold was fabricated, consists of flat wide base, stopper part and mounting part responsible for tooth mounting and replication. The tooth after preparation and finishing was duplicated 20 times by epoxy resin materials by aids of special deigned tray, to give 20 identical epoxy dies. Epoxy dies were randomly divided into two groups according to the ceramic material used as follow:

- IPS E.max CAD blocks have used for fabrication of ceramic crowns $(n=10)$.

- VITA SUPRINITY blocks have used for fabrication of ceramic crowns $(n=10)$.

Machining fabrication technique Cerec $3 \mathrm{D}$ System is used for fabrication of the twenty crowns where experimental crowns will be milled from ceramic blocks*. All crowns are etched with $9 \%$ hydrofluoric acid gel for 20 seconds, rinsed with water and dried with air. A layer of silane coupling agent is applied on the fitting surface of the crowns which is left completely to dry for 60 seconds. Each ceramic crown was cemented with self-etch self-adhesive resin cement (TOTAL CEM) under standardized static load $(70 \mathrm{~N})^{(10)}$.

The Marginal fit was evaluated by measuring the vertical marginal gap between crown margin and finish line of the prepared tooth and is determined at twelve specific locations before and after thermomechanical cycling.

The mean of all readings was calculated from the mean values of cervical circumferential measuring locations; represented the mean marginal fit value for each crown and measured by digital microscope and magnification $X 35$. The results were calculated, recorded, tabulated and submitted to statistical analysis.

All samples were subjected to thermomechanical cyclic loading 75000 cycles under $50 \mathrm{~N}$ which resemble function of 6 months using ROBOTA chewing simulator. Finally the results were calculated, recorded, tabulated and submitted to statistical analysis.

\section{RESULTS}

A. Effect of type of ceramic material on the vertical marginal gap measurements:

There was no statistical significant difference $(\mathrm{P}>0.05)$ between IPS e.max CAD group and VITA SUPRINITY group.

B. Effect of application of thermomechanical cycling on the mean of vertical marginal gap measurements:

* Sirona dental system GmbH. D-64625 Bensheiu, German 
There was no statistical significant difference $(\mathrm{P}>0.05)$ between IPS e.max CAD group measured before $(44.9 \pm 1.76 \mu \mathrm{m})$ and after $(43.9 \pm 2.28 \mu \mathrm{m})$ thermomechanical cycling. There no statistical significant difference $(\mathrm{P}>0.05)$ between VITA SUPRINITY group measured before $(46.5 \pm 1.79$ $\mu \mathrm{m})$ and after $(45.1 \pm 1.74 \mu \mathrm{m})$ thermomechanical cycling as represented in (table 1).

TABLE (1): Comparison between the vertical marginal gap measurements of the 2 studied groups represented by (Min, Max, mean and Standard deviation) according to the ceramic material used and application of thermomechanical cycling.

\begin{tabular}{|c|c|c|c|c|}
\hline \multirow{2}{*}{$\begin{array}{l}\text { Ceramic } \\
\text { material }\end{array}$} & \multirow{2}{*}{$\begin{array}{l}\text { Application of } \\
\text { thermomechanical } \\
\text { cycling }\end{array}$} & \multicolumn{2}{|c|}{$\begin{array}{c}\text { Vertical } \\
\text { marginal gap } \\
(\mu \mathrm{m})\end{array}$} & \multirow{2}{*}{$\mathrm{p}$} \\
\hline & & $\begin{array}{l}\text { Min. } \\
\text { - Max. }\end{array}$ & $\begin{array}{l}\text { Mean } \\
\pm \mathrm{SD}\end{array}$ & \\
\hline \multirow{2}{*}{$\begin{array}{l}\text { IPS e.max } \\
\text { CAD } \\
(n=10)\end{array}$} & $\begin{array}{c}\text { Before } \\
\text { thermomechanical } \\
\text { cycling }\end{array}$ & $\begin{array}{c}43.3 \\
-62.8\end{array}$ & $\begin{array}{c}44.9 \\
\pm 1.76\end{array}$ & \multirow{2}{*}{$\stackrel{*}{0}$} \\
\hline & $\begin{array}{c}\text { After } \\
\text { thermomechanical } \\
\text { cycling }\end{array}$ & $\begin{array}{c}41.2 \\
-60.3\end{array}$ & $\begin{array}{c}43.9 \\
\pm 2.28\end{array}$ & \\
\hline \multirow{2}{*}{$\begin{array}{c}\text { VITA } \\
\text { SUPRINITY } \\
(n=10)\end{array}$} & $\begin{array}{l}\text { Before } \\
\text { thermomechanical } \\
\text { cycling }\end{array}$ & $\begin{array}{c}44.1 \\
-66.2\end{array}$ & $\begin{array}{c}46.5 \\
\pm 1.79\end{array}$ & \multirow[t]{2}{*}{ * } \\
\hline & $\begin{array}{l}\text { After } \\
\text { thermomechanical } \\
\text { cycling }\end{array}$ & $\begin{array}{c}42.9 \\
-65.6\end{array}$ & $\begin{array}{c}45.1 \\
\pm 1.74\end{array}$ & \\
\hline
\end{tabular}

\section{DISCUSSION}

Recent inventions in the strengthening of dental ceramics have led to the development of metal free ceramic restorations that are biologically safe and able to withstand relatively high compressive forces under function ${ }^{(11)}$.

CAD/CAM technology was chosen to control thickness, anatomy and ensure greater accuracy, standardization, andincreasedefficiency ${ }^{(12)}$.Marginal accuracy is considered to be the major determining factor for successful clinical performance of a restoration. Increased marginal discrepancy causes accumulation of bacterial plaque which results in a high risk of periodontal diseases, secondary caries, pulpal inflammation, and eventually pulpal death and necrosis results in biologic failure. Furthermore S.Wolfart et al 2003 concluded that the marginal gap has the most clinical relevance and should be the most critical in crown evaluation therefore, the vertical marginal gap measurement was selected as the most frequently used to evaluate the fit of the restoration ${ }^{(13)}$.

The tooth chosen to represent the master die was an acrylic model of maxillary first premolar and prepared according to manufacturing instruction of lithium disilicate ceramic restoration by aids of parallometer device and special mold to give accurate mounting and preparation as well as elimination of the human errors and mistakes as much as possible ${ }^{(14)}$.

The prepared tooth was duplicated by epoxy resin material which was reported to have a modulus of elasticity similar to human dentine and have several important advantages including strength, abrasion resistance, and detail reproduction. Also duplicated epoxy resin dies are more standardized in diameter and mechanical properties than selecting natural teeth $^{(15)}$.

In this study, marginal fit was evaluated by direct viewing with external measurements using a stereo microscope at fixed magnification of $35 \mathrm{x}$ before and after thermomechanical cycling. This technique has the advantage of noninvasive, accurate and reproducible measurements and is, therefore, useful to determine the precision of fit of the whole specimen margin ${ }^{(16)}$.

However, it is difficult to repeat the measurements from an identical angle and to distinguish the real marginal gap from its projection. For this reason and for the purpose of measurements standardization, a specially designed sample positioning device (SPD) was used to hold the tested specimens in place 
allowing the repeating of the measurements from an identical angle aligned with the focal plane of the microscope ${ }^{(17)}$.

The null hypothesis of this study was accepted as there is non-statistically significant deference between the two ceramic materials used in this study regarding the vertical marginal gap measurements; also there is non-statistically significant deference between the vertical marginal gap measurements before and after thermomechanical cycling.

Regarding thermomechanical cycling, it was found that no significant effect on the marginal adaptation in both groups before and after loading. This result supported by Guess P et al. 2009 which report that the simulated five-year ageing of the all ceramic partial coverage restorations (using indenter $6 \mathrm{~mm}$ width, and $98 \mathrm{~N}$ occlusal force) had no effect on the marginal fit ${ }^{(18)}$.

Finally, considerable controversy exists in the literature regarding the ideal marginal gap for ceramic crowns, a few studies have reported that the ideal marginal gap should be 25 to $40 \mu \mathrm{m}$ for cemented restorations. Many other studies considered the marginal gap values of 100 to $200 \mu \mathrm{m}$ to be clinically acceptable for cemented restorations. More recent studies have considered the clinically acceptable values of marginal gap to be less than $100 \mathrm{~mm}$. Therefore, the results of marginal gaps for the both groups presented in this study can be considered clinically acceptable ${ }^{(19)}$.

\section{LIMITATIONS OF THIS STUDY}

1. Using only 75000 loading cycle which resembles 6 months under function, more load cycles my affect the results.

2. Only single spacer thickness (60 microns) have been evaluated. Different spacer thickness might influence the results.

3. Using different material thickness and finish line curvature may affect the results.
4. The research was done in vitro study (in vivo study gives better clinical trial and evaluation).

\section{CONCLUSION}

Within the limitations of this study, the following conclusions can be drawn:

1. IPS e.max CAD and Vita suprinity have comparable marginal adaptation and both within the clinical acceptance range.

2. There was no significant effect of thermomechanical cycling or the material type on the mean values of vertical marginal gap measurements of IPS e.max CAD or Vita suprinity groups.

\section{REFERENCES}

1. Conrad HJ, Seong WJ, Pesun IJ. Current ceramic materials and systems with clinical recommendations: a systematic review. J Prosthet Dent 2007; 98:389-404.

2. Guess PC, Selz CF, Steinhart YN, Stampf S, Strub JR. Prospective clinical split-mouth study of pressed and CAD/ CAM all-ceramic partial-coverage restorations: 7-year results. Int J Prosthodont 2013; 26: 21-25

3. Elsakaa SE, Elnaghyb AM. Mechanical properties of zirconia reinforced lithium silicate glass-ceramic. Dent Mater $2016 \mathrm{Jul} ; 32: 908-14$.

4. Sato TP, Anami LC, Melo RM, Valandro LF, Bottino MA. Effects of Surface Treatments on the Bond Strength Between Resin Cement and a New Zirconia-reinforced Lithium Silicate Ceramic. Oper Dent 2016; 41: May-Jun; 41(3):284-92.

5. Wiskott HW, Nicholls JI, Belser UC. Stress fatigue: basic principles and prosthodontics implications. Int J Prosthodont 1995; 8:105-16.

6 .Gehrt M, Wolfart S, Rafai N, Reich S, Edelhoff D. Clinicalresults of lithium-disilicate crowns after up to 9 years ofservice. Clin Oral Investig 2013; 17:275-84.

7. Wiskott HWA, Nicholls JI, Belser UC: Stress fatigue: basic principles and prosthodontic implications. Int J Prosthodont 1995; 8:105-116.

8. Kelly JR: Clinically relevant approach to failure testing of all-ceramic restorations. J Prosthet Dent 1999; 81:652-661. 
9. Zhang L, Wang Z, Chen J, et al: Probabilistic fatigue analysis of all-ceramic crowns based on the finite element method. J Biotech 2010; 43:2321-2326.

10. Carvalho AO, Brui G, Giannini M, et al: Fatigue resistance of CAD/CAM complete crowns with a simplified cementation process. J Prosthet Dent 2014; 111:310-317.

11. Lawson NC, Burgess JO. Dental ceramics: a current review. Compend Contin Educ Dent 2014; 35:161-166.

12. Beuer F, Schweiger J, Edelhoff D. Digital dentistry: an overview of recent developments for CAD/CAM generated restorations. Br Dent J. 2008; 204:505-11.

13. Wolfart S, Wegner SM, Al-Halabi A, et al.: Clinical evaluation of marginal fit of a new experimental all-ceramic system before and after cementation. Int J Prosthodont. 2003; 16: 587-592.

14. Nawafleh N, Hatamleh M, Elshiyab S, Mack F. Lithium Disilicate Restorations Fatigue Testing Parameters: A Systematic Review. J Prosthet Dent 2016;25(2):116-26.
15. Beschnidt S, Strub J. Evaluation of the marginal accuracy of different all-ceramic crown systems after simulation in the artificial mouth. J Oral Rehabil. 1999;26(7):582-93.

16. Prisco R, Cozzolino G, Vigolo P. Dimensional accuracy of an epoxy die material using different polymerization methods. Journal of prosthodontics: official journal of the American College of Prosthodontists. 2009;18(2):156-61.

17. Att H, Komine F, Gerds T, Strub J. Marginal adaptation of three different zirconium dioxide three unit fixed dental prostheses. J Prosthet Comlekoglu Dent. 2009; 101: 239-47.

18. Guess PC, Zavanelli RA, Silva N, et al: Monolithic CAD/ CAM lithium disilicate versus veneered Y-TZP crowns: comparison of failure modes and reliability after fatigue. Int J Prosthodont 2009; 23:434-442

19. Holden JE, Goldstien G, Hittelman EL, et al.: Comparison of the marginal fit of pressable ceramic to metal ceramic restorations. J Prosthodont. 2009; 18: 645-648. 